\title{
Laparoscopic Adrenalectomy for Pheochromocytoma - Intraoperative Cardiac Arrest and Cardiopulmonary Resuscitation in Lateral Position: A Case Report
}

\author{
Shaheen MSA ${ }^{\mathrm{a}}$, Sardar K ${ }^{\mathrm{b}}$, Rahman $\mathrm{MM}^{\mathrm{c}}$, Hasan $\mathrm{MQ}^{\mathrm{d}}$, Ahmed R ${ }^{\mathrm{e}}$, Uddin $\mathrm{J}^{\mathrm{f}}$
}

\begin{abstract}
Anaesthetic management of patients with large adrenal gland tumor pheochromocytoma is a challenge to the anesthesiologist, due to perioperative uncontrolled blood pressure, risk of arrhythmias and sudden cardiac arrest. Therefore, preoperative assessment and appropriate anaesthetic management are important in patients with pheochromocytoma. Laparoscopic adrenalectomy for Pheochromocytoma offers some technical advantages owing to its improved ability to visualize the contiguous anatomy and its relationship to the adrenal tumor. The decreased manipulation of the tumor during dissection of the adrenal gland has been espoused as another benefit of the laparoscopic approach. The decreased release of catecholamines and the resultant attenuation in haemodynamic liability has been a purported advantage of the laparoscopic approach. ${ }^{1,2,3,4}$ This is a case report of successful anaesthetic management of a patient with pheochromocytoma undergoing laparoscopic adrenalectomy using combined general and epidural anaesthesia the patient who developed intraoperative cardiac arrest and complete recovery after given lateral position CPR.
\end{abstract}

Keywords: Anaesthetic management, pheochromocytoma, lateral position CPR, laparoscopic adrenalectomy.

(BIRDEM Med J 2019; 9(2): 165-169)

\section{Introduction}

The term pheochromocytoma (Pheo) was coined by Pick in 1910. In 1992 L'Abbe and his colleagues first made the fascinating observation that a paroxysmal crisis of

Authors Information

a. Dr. Md. Shafiul Alam Shaheen, Assistant Professor, Department of Anaesthesiology \& Surgical ICU, Ibrahim Medical College \& BIRDEM General Hospital

b. Prof. Kawsar Sardar, Professor\& Head, Department of Anaesthesiology \& Surgical ICU, Ibrahim Medical College \& BIRDEM General Hospital

c. Dr. Md. Mushfiqur Rahman, Assistant Professor, Department of Anaesthesiology \& Surgical ICU, Ibrahim Medical College \& BIRDEM General Hospital

d. Dr. Md. Quamrul Hasan, Senior Medical Officer, Department of Anaesthesiology \& Surgical ICU, Ibrahim Medical College \& BIRDEM General Hospital

e. Dr. Raju Ahmed, Assistant Professor, Department of Anaesthesiology, Ibrahim Cardiac Hospital \& Research Institute

f. Dr. Jashim Uddin, Registrar, Department of Anaesthesiology, Ibrahim Cardiac Hospital \& Research Institute

Address of correspondence: Dr. Md. Shafiul Alam Shaheen, Assistant Professor, Department of Anaesthesiology \& Surgical ICU, Ibrahim Medical College \& BIRDEM General Hospital, Shahbagh, Dhaka, Bangladesh. E-mail: drshafiul27@yahoo.com

Received: June 9, 2018

Accepted: February 28, 2019 hypertension occurred in a 28-year-old woman and her autopsy to have a pheochromocytoma. ${ }^{5}$ Pheochromocytoma is a catecholamine-producing neuroendocrine tumor arising from the chromaffin cells of the adrenal medulla or extraadrenal paraganglia. It is a potential life-threatening disease with a high risk of cardiovascular complications such as myocardial infarction, arrhythmias, catecholamine- induced cardiomyopathy, stroke and pulmonary edema. It is a rare neoplasm, occurring in one to two per 1000 patients with hypertension. The relatively high prevalence of pheochromocytoma in autopsy studies $(0.05 \%)$ indicates that the diagnosis is often missed; the overall incidence is estimated to be 1.6 to 8 cases per million inhabitants per year. ${ }^{6}$

Traditionally, adrenalectomy for pheochromocytoma has been performed by open lateral retroperitoneal surgery. ${ }^{7}$ Nowadays, laparoscopic removal of intra adrenal and extra adrenal pheochromocytoma is the preferred surgical treatment because it reduces postoperative morbidity, hospital stay and costs compared with conventional laparotomy. ${ }^{6}$ That's why; 
laparoscopic adrenalectomy has become the standard of care for the management of functioning and nonfunctioning adrenal neoplasms with a benign appearance, d" $6 \mathrm{~cm}$ in diameter and weighing $<100 \mathrm{~g}$.

Currently indication to laparoscopic adrenalectomy for lesions $>6 \mathrm{~cm}$ is still a matter of debate and experienced endocrine surgeons are divided between supporters $8,9,10$ and detractors. ${ }^{11,12}$ Nevertheless it has been shown that laparoscopic adrenalectomy, allowing earlier mobilization, is associated with lower rates of pulmonary infections, thromboembolic complications and mortality than traditional surgery. ${ }^{13}$ Induction of general anaesthesia and surgical tumor manipulation are the most well known stimuli to evoke an acute catecholaminergic crisis. About $25 \%$ to $50 \%$ of hospital deaths of patients with pheochromocytoma occur during surgery. ${ }^{14}$

\section{Case Report}

A 37-year-old female was admitted to the urology department as a diagnosed case of pheochromocytoma, right adrenal mass. For last one year, she had experienced recurrent episode of headache, palpitation, sweating, chest discomfort, orthostatic hypotension and fatigue. The symptoms were triggered by several factors such as: physical exertion, anxiety, stress, bowel movement. Clinical examination revealed blood pressure 190/120 $\mathrm{mmHg}$ and Pulse rate 120/min. Blood investigation showed fasting blood sugar of $160 \mathrm{mg} / \mathrm{dl}$ and postprandial blood sugar of $220 \mathrm{mg} / \mathrm{dl}$.

The abdominal CT scan revealed $6 \times 5 \times 4 \mathrm{~cm}$ sized retroperitoneal mass lesion in the right para-aortic region

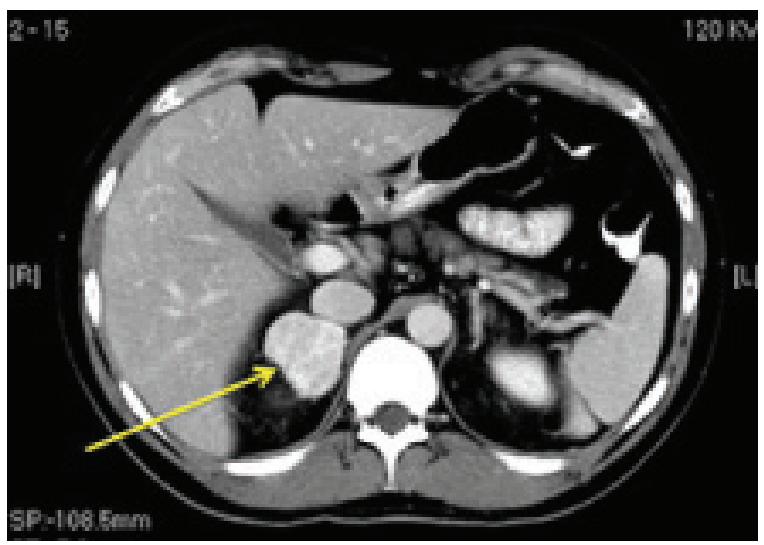

Figure 1 The abdominal CT scan revealed $6 \times 5 \times 4 \mathrm{~cm}$ sized retroperitoneal mass lesion in the right para-aortic region which was extending to the suprarenal region which was extending to the suprarenal region (Figure 1). The mass receives its arterial supply from the right renal artery. Urine and blood tests confirmed the diagnosis of a catecholamine- producing mass (mainly epinephrine and norepinephrine in a lesser degree). Measurements of catecholamines and their metabolites confirmed the diagnosis of pheochromocytoma. The plasma epinephrine level was $393 \mathrm{pg} / \mathrm{mL}$ (normal range, $<100 \mathrm{pg} / \mathrm{mL}$ ), the norepinephrine level was 9,698pg/ $\mathrm{mL}$ (normal range, 100 to $450 \mathrm{pg} / \mathrm{mL}$ ), the dopamine level was $57 \mathrm{pg} / \mathrm{mL}$ (normal range, $<20 \mathrm{pg} / \mathrm{mL}$ ), and the level of vanillylmandelic acid was $52.6 \mathrm{ng} / \mathrm{mL}$ (normal range 3 to $9 \mathrm{ng} / \mathrm{mL}$ ). Values for 24-hour urinary excretion were epinephrine 242 ìg (normal range 3 to $15 \mathrm{ig} / 24 \mathrm{~h}$ ); norepinephrine $2802 \mathrm{pg} / 24 \mathrm{~h}$ (normal range 26 to $121 \mathrm{pg} / 24 \mathrm{~h}$ ); dopamine $3124 \mathrm{ig} / 24 \mathrm{~h}$ (normal range 190 to $40 \mathrm{ig} / 24 \mathrm{~h}$ ); vanillylmandelic acid $46.6 \mathrm{mg} / 24 \mathrm{~h}$ (normal range 1.3 to $5.1 \mathrm{mg} / 24 \mathrm{~h}$ ); metanephrine $3.42 \mathrm{mg} /$ $24 \mathrm{~h}$ (normal range 0.05 to $0.23 \mathrm{mg} / 24 \mathrm{~h}$ ); and normetanephrine $7.50 \mathrm{mg} / 24 \mathrm{~h}$ (normal range 0.07 to $0.26 \mathrm{mg} / 24 \mathrm{~h}$ ). Blood count and serum electrolytes were within normal ranges. Her blood pressure was controlled by antihypertensive drugs like amlodipine $10 \mathrm{mg}$ BD, prazocin $5 \mathrm{mg}$ TDS, telmisartan $40 \mathrm{mg}$ TDS and clonidine $0.3 \mathrm{mg}$ BD. Tablet propanolol $20 \mathrm{mg}$ BD was given for control of tachycardia. For DM, regular insulin was administered. After five days, the patient was taken up for laparoscopic adrenalectomy.

Preoperative examination revealed a blood pressure of 140/85 mm Hg in the supine position (130/80 mm Hg standing upright) under combined á- and â-blockade and heart rate was 90 beat/minute. Anaesthesia was performed with propofol (2.5 mg / kg IV), fentanyl (2 ì $/ \mathrm{kg}$ IV) and Atracurium ( $0.5 \mathrm{mg} / \mathrm{kg}$ IV $)$. Infusion of propofol@0.1 - 0.2 mg/kg/min was used for maintenance along with incremental dose of atracurium when needed. After induction of anaesthesia a central venous line (triple-lumen, right Subclavian vein) and one peripheral IV line in right hand (20 gauge) were inserted.

Then the patient was placed in left lateral position and epidural catheter was inserted at $\mathrm{T}_{9} / \mathrm{T}_{10}$ level. After given the test dose ( $3 \mathrm{ml}$ lignocaine with adrenaline), $10 \mathrm{ml} 0.025 \%$ bupivacaine along with 50 ìg fentanyl was given. Then continuous epidural infusion of $0.125 \%$ bupivacaine with 1 ìg fentanyl@4-8 ml/hr started. Pneumoperitoneum was made by $\mathrm{CO}_{2}$ insufflation and 
intra abdominal pressure (IAP) was maintained 10 - 12 $\mathrm{mm} \mathrm{Hg}$. The patient's blood pressure and heart rate remained stable during induction and positioning (left lateral and head up). After surgery started about 20 minutes later when continuing surgical dissection of the tumor, the patient's blood pressure increases from 165/ 95 to $200 / 105 \mathrm{~mm} \mathrm{Hg}$ and heart rate increases 150 to 170 beat $/ \mathrm{min}$. Inj. labetalol $10 \mathrm{mg} \& \mathrm{inj}$. propofol $50 \mathrm{mg}$ bolus given immediately. But heart rate \& blood pressure was still rising to $180-200$ beat $/ \mathrm{min}$ and $240 / 115 \mathrm{~mm}$ $\mathrm{Hg}$ respectively. Again Inj. labetalol $10 \mathrm{mg} \&$ inj.propofol $50 \mathrm{mg}$ bolus given. But within $30-45$ second patient developed ventricular fibrillation followed by asystole. Immediately shouting for help, stop surgery \& relief of gas pressure. Carotid pulse was checked \& the carotid pulse was absent, ECG showed straight line, immediately start CPR in left lateral position as patient was in same position and inj. Adrine $1 \mathrm{mg}$ IV given. CPR continued \& after about 1 - 2 minute, carotid pulse came \& ECG showed QRS complex. QRS complex was regular and heart rate was 150 - 160 beat $/ \mathrm{min}$, blood pressure was 180/110 mm $\mathrm{Hg}$. Immediately arterial blood sample was sent. Arterial blood gas analysis showed normal $(\mathrm{pH}=7.43, \mathrm{PaCO} 2$ $=36 \mathrm{~mm} \mathrm{Hg}, \mathrm{PaO} 2=175 \mathrm{~mm} \mathrm{Hg}, \mathrm{HCO}-=24 \mathrm{mmol} /$ $1, \mathrm{BE}=0.5 \mathrm{mmol} / \mathrm{l})$. After 10 minute her heart rate \& blood pressure were 120 beat $/ \mathrm{min} \& 150 / 100 \mathrm{~mm} \mathrm{Hg}$ respectively. After 15 minutes her heart rate was 110 beat $/ \mathrm{min}$ and blood pressure was $140 / 90 \mathrm{~mm} \mathrm{Hg}$. Then again Pneumoperitoneum was made and surgery was continued. Total duration of surgery was 140 minutes including resuscitation time. After completing the surgery the patient was extubated smoothly. In recovery period the patient was fully conscious, oriented and response on command. Her vitals were heart rate 100 beat/min, blood pressure $140 / 80 \mathrm{~mm} \mathrm{Hg}$, respiratory rate $18 / \mathrm{min}$. Then the patient was shifted to Surgical ICU for better management. After $1^{\text {st }}$ POD the patient was transferred to ward.

\section{Discussion}

Phaeochromocytoma is a rare, catecho-lamine-secreting tumour arising from the adrenal medulla. The most common symptom of phaeo-chromocytoma is sustained or paroxysmal hypertension, episodic headache, sweating and palpitations. Other symptoms like generalized weakness, tremor and pallor are also sometimes found. Following biochemical confirmation of the diagnosis, clinical practice guidelines recommend CT scanning of the adrenal glands as the initial imaging test, however MRI should be considered when there is evidence of metastatic disease.

The definitive treatment for phaeo-chromocytoma is surgical removal of the tumour. The first successful surgical removal of the pheochromocytoma was performed by Roux in 1926. The first laparoscopic adrenalectomy (LA) was performed by Gagner and his colleagues in $1992 .{ }^{15}$ Laparoscopy offers a better anatomical exposure, a shorter length of stay, a decrease in postoperative pain, faster return to the preoperative activity level, improved cosmesis, and reduced blood loss, early to resumption of oral feeding. ${ }^{16,17}$

Haemodynamic instability, in particular intraoper-ative tachycardia \& hypertension, are common during phaeochromocytoma surgery due to an exaggerated release of catecholamines occurring throughout the different stages of airway manipulation \& surgery, tilting to the surgical position, $\mathrm{CO}_{2}$ insufflation, and tumor manipulation. ${ }^{18,19}$ Mikami et al. ${ }^{20}$ reported that the plasma levels of epinephrine and norepinephrine increased immediately after $\mathrm{CO} 2$ insufflation during pneumoperitoneum, and that the elevation of catecholamine levels was greater when the patient was in a semi lateral position than in a trendelenburg position. Intraoperative hyper-tension can be severe and sustained, often requiring the use of potent antihypertensive agents to control it. ${ }^{21}$

Laparoscopic adrenalectomy has recently gained widespread acceptance as a safe and less-invasive procedure than open adrenalectomy. Guazzoni et al. ${ }^{22}$ retrospectively compared laparoscopic versus open adrenalectomy in 40 patients with benign, hyper functioning, unilateral adrenal tumors. Postoperative morbidity was markedly decreased after laparoscopic adrenalectomy compared to that after an open operation, because the intervals to oral intake and ambulation, hospital discharge, and return to preoperative normal activity were shorter with laparoscopy. Orchard et al. ${ }^{23}$ noted that currently, the diagnosis, localization, preoperative blockade, intraoperative hemodynamic control, and postoperative management have reached a level sufficient to permit a laparoscopic approach.

Pneumoperitoneum induced during laparoscopic adrena-lectomy, and in particular, handling of the 
phaeochromocytoma tumor can result in marked catecholamine release resulting in severe hypertension. Effective intra-operative management of $\mathrm{BP}$ is therefore crucial during phaeochromocytoma surgery. Careful handling of the tumour tissue, limited intra-abdominal pressure, adequate anaesthesia and the use of vaso-active agents are important components of achieving intraoperative BP stability and reducing the risk of complications secondary to elevated intraoperative BP. Rapid-acting antihypertensive agents that allow for a reduction of BP, without exerting a prolonged effect, can be particularly beneficial at the time of tumour removal.

Early initiation of cardiopulmonary resuscitation (CPR) results in more favorable outcome. CPR is most effective in supine position. There are no recommendations about initiation of CPR in case of cardiac arrest happens during surgery, in a position other than supine. We describe the successful resuscitation, after initiation of CPR in left lateral position, in a patient who developed asystole while undergoing laparoscopic adrenalectomy. There are only two reports of successful CPR in right lateral position. Bengali, et al. ${ }^{24}$ have described CPR in lateral position, during renal surgery, with the palm of dominant hand over patient's mid-thoracic spine and other hand directly opposite against the sternum to compress the chest between the two palms. ${ }^{24}$

To perform high-quality CPR, adequate monitoring and feedback is important, especially when CPR is delivered under unusual circumstance. Recent consensus 25 emphasizes the importance of monitoring a patient's response to resuscitation. A complete recovery, without any postoperative neurologic deficits, combined with lack of clinical or laboratory evidence of tissue ischemia or infarction, suggests that adequate tissue perfusion and oxygenation were achieved during resuscitation performed in the left lateral position. So Successful recovery without any neurological complication suggests effective CPR was performed in the left lateral position.

\section{Conclusion}

Early initiation of Cardiopulmonary resuscitation (CPR) results in more favorable outcome. To perform highquality CPR, adequate monitoring and feedback is important, especially when CPR is delivered under unusual circumstance. We described the successful resuscitation, after initiation of CPR in left lateral position, in a patient who developed asystole while undergoing laparoscopic adrenalectomy for pheochromocytoma.

Conflict of interest: Nothing to declare.

\section{References}

1. Meurisse M, Joris J, Hamoir E, Hubert B, Chartier C. Laparoscopic removal of pheochromocytoma: why? when? and who? (Reflections on one case report). Surg Endosc. 1995; 9:431-436.

2. Col V, de Canniere L, Collard E, Michel L, Donckier J. Laparoscopic adrenalectomy for phaeochromocytoma: endocrinological and surgical aspects of a new therapeutic approach. Clin Endocrinol (Oxf). 1999; 50:121-125.

3. Fernandez-Cruz L, Tuara P, Saenz A, Benarroch G, Sabater L. Laparoscopic approach to pheochromocytoma: hemodynamic changes and catecholamine secretion. World J Surg. 1996; 20:762-768.

4. Li ML, Fitzgerald PA, Price DC, Norton JA. Iatrogenic pheochromocytosis: a previously unreported result of laparoscopic adrenalectomy. Surgery. 2001; 130:1072-1077.

5. Manger WM, Gifford RW. Pheochromocytoma. 1st ed, New York: Springer-Verlag; 1977.

6. Lenders JW, Eisenhofer G, Mannelli M, Pacak K: Phaeochromocytoma. Lancet 2005; 366:665-675.

7. Prys-Roberts $\mathrm{C}$ : Phaeochromocytoma-recent progress in its management. Br J Anaesth 2000; 85:44-57.

8. Sharma R, Ganpule A, Veeramani M, Sabnis RB, Desai M: Laparoscopic management of adrenal lesions larger than 5 $\mathrm{cm}$ in diameter. Urol J 2009; 6(4):254-259, Fall.

9. Lombardi CP, Raffaelli M, De Crea C, Traini E, D’Amore AM, Bellantone R: Pheochromocytoma: role of preoperative diagnosis in the assessment of malignancy risk and in the choice of surgical approach. Suppl Tumori 2005; 4(3):S211, May-Jun.

10. Conzo G, Musella M, Corcione F, De Palma M, Ferraro F, Palazzo A, Napolitano S, Milone M, Pasquali D, Sinisi AA, Colantuoni V, Santini L: Laparoscopic adrenalectomy, a safe procedure for pheochromocytoma. A retrospective review of clinical series. Int J Surg 2013; 11:152-156.

11. Cheah WK, Clark OH, Horn JK, Siperstein AE, Duh QY: Laparoscopic adrenalectomy for pheochromocytoma. World J Surg 2002; 26(8):1048-51, Aug.

12. Li ML, Fitzgerald PA, Price DC, Norton JA: Iatrogenic pheochromocytomatosis: a previously unreported result of laparoscopic adrenalectomy. Surgery 2001; 130(6):10721077, Dec.

13. Murphy MM, Witkowski ER, Ng SC, Mc Dade TP, Hill JS, Larkin AC, Whalen GF, Litwin DE, Tseng JF: Trends in adrenalectomy: a recent national review. Surg Endosc 2010; 24(19):2518-2526. 
14. Fleisher LA: Diseases of the endocrine system. In Anaesthesia in Uncommon Diseases.. 5 edition. Edited by: Fleisher LA. St. Louis: Saunders Elsevier. 2006;440-443.

15. Gagner M, Lacroix A, Bolte E. Laparoscopic adrenalectomy in Cushing's syndrome and pheochromocytoma. NEJM. 1992; $327: 1033$.

16. Mac Gillivary DC, Shichman SJ, Ferrer FA, Malchoff CD. A comparison of open vs Laparoscopic adrenalectomy. Surg Endosc. 1996; 10:987-90.

17. Gagner M. Laparoscopic adrenalectomy. Surg Clin North Am. 1996; 76:523-37.

18. Assalia A, Gagner M. Laparoscopic adrena-lectomy. Br J Surg. 2004; 91:1259-74.

19. Joris JL, Hamoir EE, Hart-stein GM, etal. Hemo-dynamic changes and catecholamine release during laparoscopic adrenalectomy for pheo-chromocytoma. Anesth Analg. 1999;88:16-21.

20. Mikami 0, Kawakita S, Fujise $\mathrm{I}<$, Shingu K, Takahashi $\mathrm{H}$, Matsuda T. Catecholamine release caused by carbondioxide insufflation during laparoscopic surgery. J Urol 1996; 155:1368-1371.
21. Kinney MA, Warner ME, vanHeerden JA, et al. Perianesthetic risks and outcomes of pheochromocytoma and paraganglionoma resection. Anesth Analg. 2000;91:1118-23.

22. Guazzoni G, Montorsi F, Bocciardi A, Da Pozzo L, Rigatti P, Lanzi R, Pontiroli A. Transperitoneal laparoscopic versus open adrenalectomy for benign hyperfunctioning adrenal tumors: a comparative study.J Urol 1995;153:1597-1600.

23. Orchard T, Grant CS, van Heerden JA, Weaver A. Pheochromocytoma-continuing evolution of surgical therapy. Surgery 1993; 114:1153-1159.

24. Bengali R, Janik LS, Kurtz M, McGovern F, Jiang Y (2014) Successful cardiopulmonary resuscitation in the lateral position during intraoperative cardiac arrest. Anesthesiology 120(4): 1046-1049.

25. Meaney PA, Bobrow BJ, Mancini ME, Christenson J, de Caen AR, Bhanji F, Abella BS, Kleinman ME, Edelson DP, Berg RA, Aufderheide TP, Menon V, Leary M, CPR Quality Summit Investigators, the American Heart Association Emergency Cardiovascular Care Committee, and the Council on Cardiopulmonary, Critical Care, Perioperative and Resuscitation. Cardiopulmonary resuscitation quality: Improving cardiac resuscitation outcomes both inside and outside the hospital: a consensus statement from the American Heart Association. Circulation. 2013; 128(4):417-35. 